\title{
Development of a safe live Leishmania vaccine line by gene replacement
}

(trypanosomatid protozoan parasite/dihydrofolate reductase-thymidylate synthase/mouse/macrophage/auxotrophic mutant)

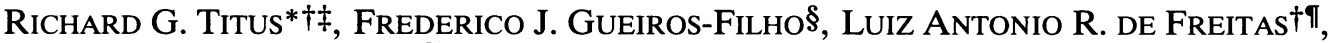 \\ AND STEPHEN M. BEVERLEY§॥
}

${ }^{*}$ Department of Pathology, College of Veterinary Medicine and Biomedical Sciences, Colorado State University, Fort Collins, CO 80523 ; ${ }^{\dagger}$ Department of Tropical Public Health, Harvard School of Public Health, Boston, MA 02115; and §Department of Biological Chemistry and Molecular Pharmacology, Harvard Medical School, Boston, MA 02115

Communicated by William Trager, The Rockefeller University, New York, NY, August 7, 1995

\begin{abstract}
Vaccination with live Leishmania major has been shown to yield effective immunization in humans; however, this has been discontinued because of problems associated with virulence of the available vaccine lines. To circumvent this, we tested the ability of a dhfr-ts ${ }^{-}$null mutant of $L$. major, obtained by gene targeting, to infect and then to vaccinate mice against challenge with virulent $L$. major. Survival and replication of $d h f r-t s^{-}$in macrophages in vitro were dependent upon thymidine, with parasites differentiating into amastigotes prior to destruction. dhfr-ts $^{-}$parasites persisted in BALB/c mice for up to 2 months, declining with a half-life of 2-3 days. Nonetheless, $\mathrm{dhfr}^{-t \mathrm{~s}^{-}}$was incapable of causing disease in both susceptible and immunodeficient $(n u / n u)$ BALB/c mice. Animal infectivity could be partially restored by thymidine supplementation. When inoculated by the i.v., s.c., or i.m. routes into mice, $d h f r-t s^{-}$could elicit substantial resistance to a subsequent challenge with virulent L. major. Thus, Leishmania bearing auxotrophic gene knockouts can be safe and induce protective immunity. Potentially, dhfr-ts ${ }^{-}$could be used as a platform for delivery of immunogens relevant to other diseases.
\end{abstract}

Protozoan parasites of the genus Leishmania reside within macrophages, where in humans they induce a spectrum of diseases ranging from mild cutaneous to lethal visceral forms. When infected with Leishmania, especially species causing cutaneous disease, most humans mount an effective response that resolves the infection and confers solid immunity to reinfection (1-4). This suggested that among the parasitic diseases of humans, Leishmania would be one for which a vaccine could be developed with relative ease. However, there is still no safe and effective vaccine.

In some areas individuals deliberately infect themselves with virulent Leishmania major on regions of the body where resultant scarring is hidden (a practice known as "leishmanization"; refs. 3 and 5). This usually leads to solid immunity; however, infections induced in this manner can prove as troublesome as naturally acquired disease. These problems led many workers to attempt vaccination by attenuated/avirulent forms of Leishmania. For example, $\gamma$-irradiated $L$. major elicit substantial protection in mice to challenge with virulent $L$. major (ref. 6; for review, see ref. 7). Similar results have been obtained with attenuated Leishmania derived by long-term culture in vitro (8-11), selection for temperature sensitivity (12), or chemical mutagenesis $(9,13,14)$. Unfortunately, the attenuating defect in these lines has not been defined, and they can revert toward virulence and/or persist for long periods of time $(6,15)$. Persistence of asymptomatic Leishmania infections raises the risk of subsequent reactivation, especially in

The publication costs of this article were defrayed in part by page charge payment. This article must therefore be hereby marked "advertisement" in accordance with 18 U.S.C. $\$ 1734$ solely to indicate this fact.
AIDS (16-21) where leishmaniasis is an opportunistic infection. These problems led to current efforts to develop purified molecules as immunogens or to engineer their delivery with live vaccine vehicles such as Salmonella or bacillus CalmetteGuérin (BCG) $(22,23)$. However, the use of a live Leishmania vaccine might still be superior if it could be made safe.

To overcome the problem of safety, we have taken advantage of the availability of nonrevertible auxotrophic mutants obtained by gene targeting. In this work we have tested the safety and vaccination potential of a conditional auxotroph of L. major $\left(d h f r-t s^{-}\right)$produced by targeted deletion of an essential metabolic gene, DHFR-TS (dihydrofolate reductasethymidylate synthase; refs. 24 and 25). The results of these studies are encouraging, as $d h \mathrm{fr}^{-} \mathrm{ts}^{-}$was incapable of causing disease in even the most susceptible mouse strain, yet conferred substantial protective immunity in mice subsequently challenged with virulent parasites.

\section{MATERIALS AND METHODS}

dhfr-ts ${ }^{-}$L. major E10-5A3 was derived from L. major CC-1 (25) by two rounds of targeted gene replacement and bears integrated G418 and hygromycin drug-resistance markers replacing the two DHFR-TS alleles. CC-1 is a clone of strain LT252 (MHOM/IR/83/LT252; ref. 26). Virulent challenge $L$. major was clone 5 of the LV39 line (Rho/SU/59/P; ref. 13); it was passed through mice every 4 weeks to maintain virulence. When propagated for immunization or challenges, Leishmania were grown on biphasic NNN medium (ref. 27; thymidine at $10 \mu \mathrm{g} / \mathrm{ml}$ was added for $d h f r-t s^{-}$). Metacyclic dhfr-ts ${ }^{-}$promastigotes were purified by using peanut agglutinin (28) and a freeze-thaw lysate was made (27). BALB/c and $\mathrm{BALB} / \mathrm{c}$ athymic $n u / n u$ mice were obtained from the National Cancer Institute (Frederick, MD); CBA/T6 mice were obtained from The Jackson Laboratory. Subcutaneous injections were delivered at a shallow site in the hind footpad, i.v. inoculations were into the tail vein, and i.m. injections were into the large rear leg muscle mass. Lesion progression was followed by using a vernier caliper (27). Macrophages were elicited with starch in the peritoneum of BALB/c mice, harvested, and infected with parasites, and their parasite burden was assessed as described (29). The limiting dilution assay for enumerating parasites in infected mouse tissues was performed as described (17). Lymph node cell proliferation assays were performed as described (14). Osmotic pumps (14-day Alzet model 2002; Alza) were loaded with thymidine

¥To whom reprint requests should be sent at the $*$ address.

TPresent address: Centro de Pesquisas Goncalo Moniz, Fundacao Oswaldo Cruz, Rua Valdemar Falcao, 121-Brotas, Salvador, Bahia, Brazil, CEP 41.945.

"To whom reprint requests should be addressed. 
at $42 \mathrm{mg} / \mathrm{ml}$ and implanted 1 day prior to infection with dhfr-ts ${ }^{-}$.

\section{RESULTS}

Inability of $\boldsymbol{d h f r}-\boldsymbol{t s}^{-}$to Replicate in Macrophages in Vitro. This laboratory has shown $(24,25)$ that $d h f r-t s^{-} L$. major is auxotrophic for thymidine as the free-living promastigote form in vitro. By analogy with other thymidine auxotrophs (30), we expected that $d h f r-t s^{-}$would not replicate in macrophages in vitro or survive when inoculated into mice. This was tested by using BALB/c mice or macrophages, which are very susceptible to $L$. major infection (1).

Starch-elicited peritoneal macrophages were infected in vitro with virulent Leishmania (LV39 clone 5) or dhfr-ts ${ }^{-}$. Both lines were taken up by macrophages (Fig. $1 A, 24-\mathrm{hr}$ data). Beyond $24 \mathrm{hr}$, virulent Leishmania continued to replicate as amastigotes within macrophages. In contrast, $d h \mathrm{fr}_{\mathrm{r}} \mathrm{ts}^{-}$did not replicate and were slowly destroyed. Significantly, after 24 or $48 \mathrm{hr}, d h f r-t s^{-}$within macrophages appeared morphologically as amastigotes, even in the absence of thymidine (Fig. $1 B$ ). To confirm that the destruction of $d h f r-t s^{-}$arose specifically from the lack of $D H F R-T S$, we added thymidine $(100 \mu \mathrm{g} / \mathrm{ml})$ to the medium, which restored both survival and replication (Fig. 1A).

Inability of $\boldsymbol{d h} \boldsymbol{h} \boldsymbol{r}$-ts $\boldsymbol{s}^{-}$to Cause Disease in Mice. We next tested whether $d h f r-t s^{-}$was able to infect BALB/c mice, by inoculating stationary-phase parasites s.c. into one hind footpad. Stationary-phase organisms were used as this provides the infective metacyclic stage (28) of $L$. major (typically $5 \%$ for $\left.d h f r-t s^{-}\right)$.
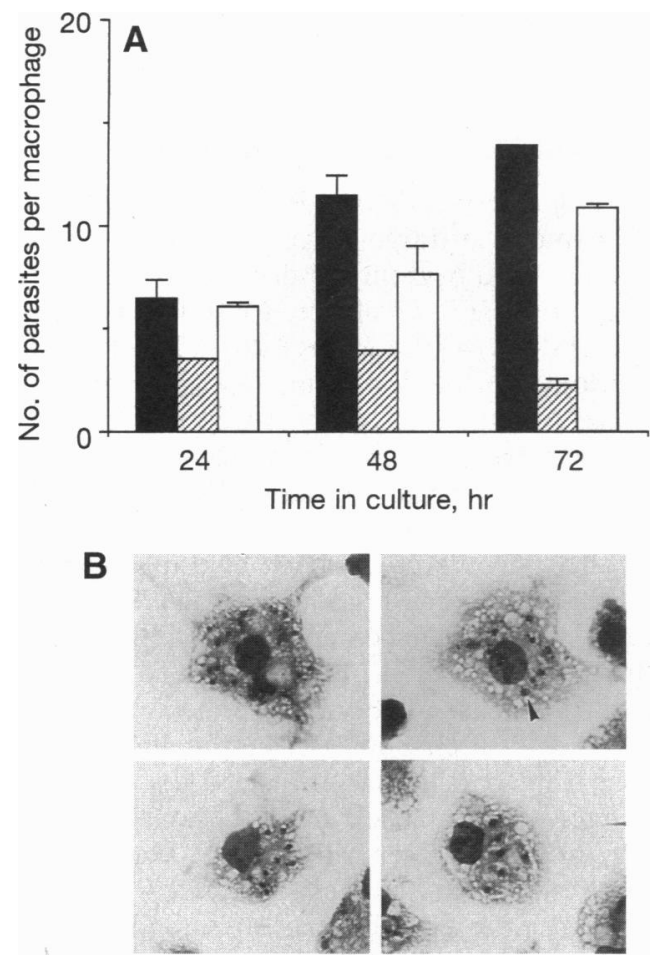

FIG. 1. $d h f r-t s^{-}$differentiates into amastigotes within macrophages in vitro but is unable to replicate. $(A)$ Murine peritoneal macrophages were infected with stationary-phase L. major (multiplicity of infection $=10$ ). At the indicated times, intracellular parasites were counted as described (29). Results are shown as the mean \pm SEM. Solid bars, virulent LV39 L. major; hatched bars, dhfr-ts ${ }^{-}$; open bars, dhfr-ts ${ }^{-}$ infections performed in the presence of thymidine at $100 \mu \mathrm{g} / \mathrm{ml}$. (B) Macrophages infected with $d h f r-t s^{-}$in the absence of thymidine for 24-48 hr were fixed and stained as described (29). Arrowhead marks one of the many amastigote-stage $d h f r-t s^{-}$evident in these preparations. dhfr-ts ${ }^{-}$was derived from the CC-1 line of $L$. major, which is less infective than virulent LV39 clone 5 and requires $\approx 10$-fold more inoculating parasites to give a similarly rapid progression of disease (ref. 31 and Fig. $2 A$ ). Large numbers ( $10^{8}$ cells per mouse) of $d h f r-t s^{-}$did not induce cutaneous lesions, even after 2.5 years. In contrast, $10^{7}$ virulent LV39 or $10^{8}$ parental CC-1 parasites gave severe disease, with lesions that progressed rapidly and at similar rates. Inoculation of only $10^{6}$ CC- 1 parasites yielded lesions after a delay of $\approx 90$ days.

In several experiments we attempted to rescue the $d h f r-t s^{-}$ phenotype in vivo, by implanting osmotic pumps that delivered thymidine at the maximum tolerated dose for either 14 or 28 days. Small lesions (up to $0.25 \mathrm{~mm}$ ) were obtained after infection with $10^{8} \mathrm{dhfr}^{-t^{-}}$(data not shown). The small size relative to infection with $\mathrm{CC}-1$ (Fig. $2 A$ ) may be due to $(i)$ the rapid clearance of thymidine from the bloodstream (32), (ii) difficulty in delivering thymidine to the Leishmania phagolysosomal compartment, and/or (iii) a need in vivo but not in vitro for reduced folates, beyond the capacity of the alternative pteridine reductase PTR1 (33). Significantly, upon removal of the thymidine pumps, $d h f r-t s^{-}$lesions regressed immediately and disappeared within 2 weeks (data not shown).

Finally, we tested whether $d h f r-t s^{-}$would induce cutaneous lesions in BALB/c athymic $n u / n u$ mice, which are severely immunocompromised and the most permissive host known for L. major. Cutaneous lesions did not occur for 220 days after infection with $10^{8}$ dhfr-ts ${ }^{-}$(data not shown), the maximum observation period since $n u / n u$ mice die prematurely.

dhfr-ts ${ }^{-}$Persist Briefly After Mouse Infection. The studies above addressed infectivity by the criterion of visible lesion development. Since Leishmania can persist in the absence of overt disease (16-21), we measured the number of viable $d h f r-t s^{-}$parasites after infection. Susceptible BALB/c mice were injected s.c. in one hind footpad with $10^{8} \mathrm{dhfr-ts^{- }}$ parasites and, at various intervals, were sacrificed, and parasites were enumerated in the footpad and the draining lymph node. The $d h f r-t s^{-}$parasites persisted for nearly 2 months, although their numbers declined rapidly with a half-life of 2-3
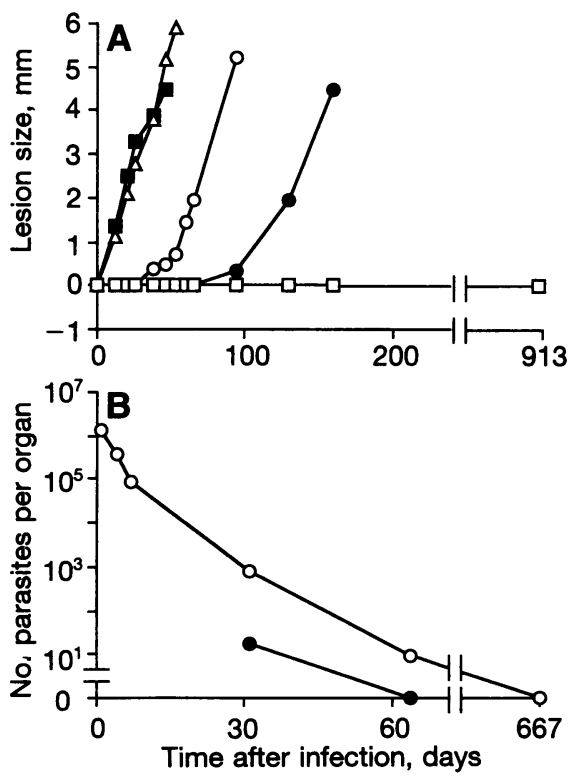

FIG. 2. Transient survival and inability of $d h f r-t s^{-}$parasites to induce cutaneous leishmaniasis in mice. $(A)$ Groups of four BALB/c mice each were injected s.c. in the hind footpad with $10^{7} \mathrm{LV} 39(\square) ; 10^{6}$ $(\bullet), 10^{7}(\bigcirc)$, or $10^{8}(\triangle)$ CC-1; or $10^{8}$ dhfr-ts $^{-}(\square)$. Lesion development was followed. (B). BALB/c mice were injected s.c. with $10^{8} d h f r-t s^{-}$. Periodically, two mice were sacrificed and parasites were enumerated from the foot $(\bigcirc)$ or draining lymph node $(\bullet)$ by limiting dilution analysis in medium supplemented with thymidine at $10 \mu \mathrm{g} / \mathrm{ml}$. 

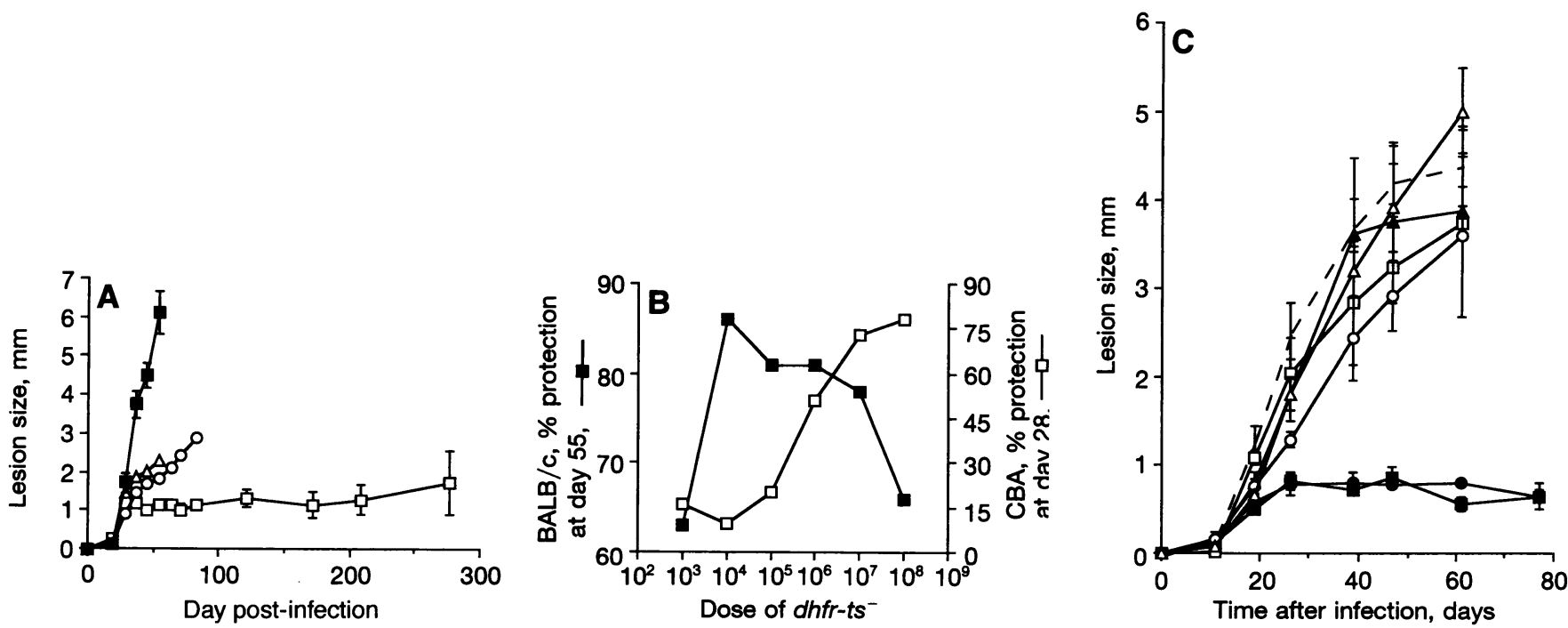

Fig. 3. Vaccinating BALB/c mice with $d h f r-t s^{-}$i.v. induces substantial immunity to virulent $L$. major. All results shown are representative of two or three experiments. $(A)$ Groups of four mice were vaccinated i.v. with $0(\square), 10^{3}(\triangle), 10^{5}(\square)$, or $10^{8}(O)$ stationary dhfr-ts ${ }^{-}$and challenged s.c. 1 week later in one hind footpad with $10^{6}$ virulent LV39 L. major, and the lesion size was measured over time. Experiments with $10^{3}$ and $10^{8}$ challenge parasites were terminated at the last data point shown; in other experiments they progress to massive lesions. $(B)$ The percent in lesion size reduction obtained by i.v. vaccination of BALB/c $(\square)(A)$ and CBA ( $\square$ ) (Fig. $4 A$ ) mice is shown. $(C)$ Groups of four mice were vaccinated with the indicated parasites, challenged 1 week later, and followed as described in $A$. Parasites were $10^{6}$ stationary $d h f r-t s^{-}$i.v. ( $\square$ ) or s.c. ( $\square$ ); $10^{6}$ metacyclic $d h f r-t s^{-}$i.v. $(\bullet)$ or s.c. $(\bigcirc)$; lysate of $10^{6}$ metacyclic $d h f r-t s^{-}$i.v. $(\Delta)$ or s.c. $(\triangle)$. Nonvaccinated control mice are shown by the dashed line.

days (Fig. 2B). From the macrophage results (Fig. 1), we infer that the persisting parasites were amastigotes.

Vaccinating BALB/c Mice with $d$ hfr-ts ${ }^{-}$i.v. Induces Substantial Immunity to Virulent $L$. major. While the $d h f r-t s^{-}$line persists briefly in mice, it does not cause disease. To test its ability to induce protective immunity, we vaccinated BALB/c mice with stationary-phase $d h f r-t s^{-}$and challenged them 1 week later with $10^{6}$ virulent $L$. major, delivered s.c. Vaccination i.v. induced high levels of immunity (Fig. $3 A$ ), consistent with previous studies showing this to be the most effective route to induce immunity against $L$. major in mice $(7,8,13)$. The most striking results were achieved with intermediate doses of $d h f r-t s^{-}\left(10^{5}-10^{6}\right.$ parasites, Fig. $\left.3 B\right)$. For example, animals vaccinated with $10^{5} \mathrm{dhfr}-\mathrm{ts}^{-}$controlled lesion development for 277 days (Fig. 3A). The basis for the dose dependency has not been studied but is interesting in light of the results of Bretscher et al. (34) who showed that administrating low doses of virulent $L$. major conferred protection to BALB/c and CBA mice.

With BALB/c mice, vaccination with purified metacyclic $d h f r-t s^{-}$was no more effective than stationary-phase $d h f r-t s^{-}$, and a metacyclic $d h f r-t s^{-}$lysate did not confer protection (Fig. $3 C$ ). Other workers have also reported that parasite lysates are ineffective $(10,35)$. Similar results were obtained when mice were challenged 1 month after vaccination (data not shown). Vaccination by the s.c. route imparted minimal protection (Fig. 3C).

There was a correlation between lesion size and parasite burden in vaccinated BALB/c mice (Fig. $3 C$ and Table 1 ). In mice vaccinated with stationary-phase $d h f r-t s^{-}$, the parasite burden was reduced 158 -fold at day 34 and 1900-fold at day 62 of infection (Table 1).

Vaccinating CBA Mice with $\boldsymbol{d h f r}$-ts ${ }^{-}$i.v., s.c., or i.m. Induces Substantial Immunity. We vaccinated resistant CBA mice with $d h f r-t s^{-}$, as the disease progression in this strain more closely resembles that observed in human infections. In these experiments, we vaccinated with stationary-phase $d h f r-t s^{-}$and challenged with virulent $L$. major after 1 week. Similar results were obtained after vaccination with purified metacyclics and challenge after 1 month (data not shown).
Like BALB/c mice, i.v. vaccination of CBA mice with $d h f r-t s^{-}$was highly protective (Fig. $4 A$ ). Unlike BALB/c mice, CBA mice were protected best by large doses of $d h \mathrm{fr}^{-} \mathrm{ts}^{-}\left(10^{8}\right.$; Figs. $4 A$ and $3 B$ ). Significantly, vaccination of $C B A$ mice with $10^{8} \mathrm{dhfr}$-ts ${ }^{-}$by either the s.c. or i.m. routes was protective (Fig. $4 B$ and $C$ ), although less so than by the i.v. route (Fig. $4 A$ ). Lower doses of $d h f r-t s^{-}$induced less protection by the s.c. or i.m. routes (data not shown). The parasite burden was decreased in all vaccinated animals, as much as 22 -fold in mice vaccinated by the i.v. route and 16 -fold by the s.c. route (Table 1).

To test the specificity of the immune response to $d h f r-t s^{-}$, draining lymph node cells were recovered 1 week after s.c. vaccination of CBA mice with $10^{8} d h f_{r}-t s^{-}$and tested for stimulation by several antigen preparations. Neither bacillus Calmette-Guérin $\left(5 \times 10^{5}\right.$ cells per $\left.\mathrm{ml}\right)$ nor ovalbumin $(250$ $\mu \mathrm{g} / \mathrm{ml})$ induced proliferation as measured by $\left[{ }^{3} \mathrm{H}\right]$ thymidine incorporation $(1100 \pm 1000 \mathrm{cpm}$ or $2600 \pm 1100 \mathrm{cpm}$, respec-

Table 1. Parasite burden in $d h f r-t s^{-}$-vaccinated mice

\begin{tabular}{|c|c|c|c|}
\hline $\begin{array}{l}\text { Mouse } \\
\text { strain }\end{array}$ & Vaccination & $\begin{array}{l}\text { Days after } \\
\text { challenge }\end{array}$ & $\begin{array}{l}\text { No. of } L . \text { major per } \\
\quad \text { lesion }\left(\times 10^{-5}\right)\end{array}$ \\
\hline $\mathrm{BALB} / \mathrm{c}$ & None & 34 & 410 \\
\hline $\mathrm{BALB} / \mathrm{c}$ & Stationary, $10^{6}$, i.v. & 34 & 2.6 \\
\hline $\mathrm{BALB} / \mathrm{c}$ & Metacyclic, $10^{6}$, i.v. & 34 & 21 \\
\hline $\mathrm{BALB} / \mathrm{c}$ & $\begin{array}{l}\text { Metacyclic lysate, } \\
10^{6} \text {, i.v. }\end{array}$ & 34 & 150 \\
\hline $\mathrm{BALB} / \mathrm{c}$ & None & 62 & 770 \\
\hline $\mathrm{BALB} / \mathrm{c}$ & Stationary, $10^{6}$, i.v. & 62 & 0.4 \\
\hline $\mathrm{BALB} / \mathrm{c}$ & Metacyclic, $10^{6}$, i.v. & 62 & 6.1 \\
\hline $\mathrm{BALB} / \mathrm{c}$ & $\begin{array}{l}\text { Metacyclic lysate, } \\
10^{6} \text {, i.v. }\end{array}$ & 62 & 500 \\
\hline CBA & None & 21 & 8.7 \\
\hline CBA & Stationary, $10^{8}$, i.v. & 21 & 0.9 \\
\hline CBA & Stationary, $10^{8}$, s.c. & 21 & 3.6 \\
\hline CBA & Stationary, $10^{8}$, i.m. & 21 & 2.1 \\
\hline CBA & None & 36 & 6.5 \\
\hline CBA & Stationary, $10^{8}$, i.v. & 36 & 0.3 \\
\hline CBA & Stationary, $10^{8}$, s.c. & 36 & 0.4 \\
\hline CBA & Stationary, $10^{8}$, i.m. & 36 & 1.3 \\
\hline
\end{tabular}




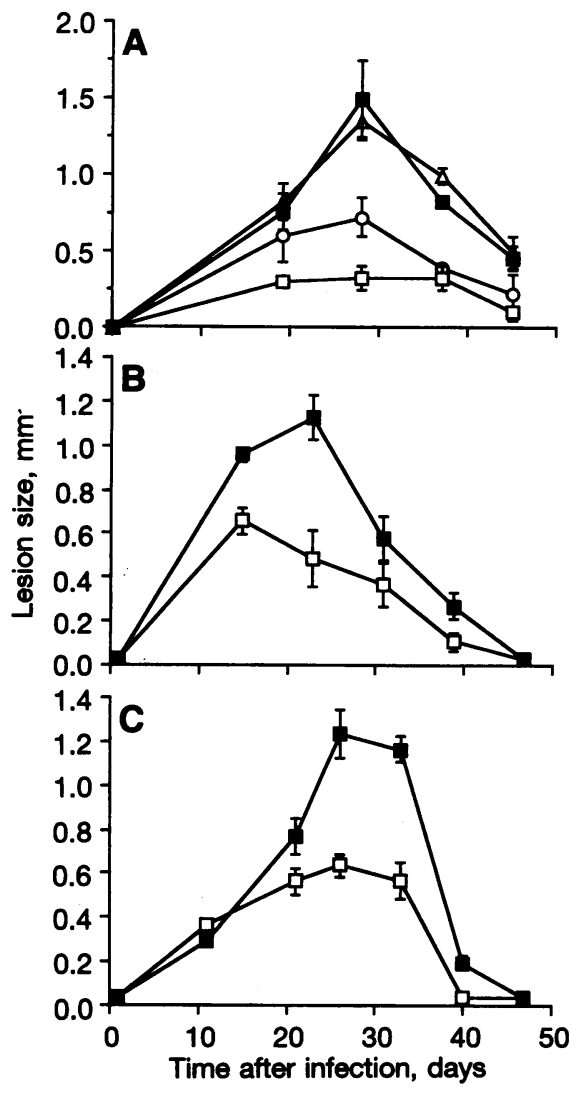

FIG. 4. Vaccinating CBA mice with $d h f r-t{ }^{-}$i.v., s.c., or i.m. induces substantial immunity to virulent $L$. major. Groups of four mice were vaccinated with $10^{8}(\square), 10^{6}(O)$, or $10^{4}(\triangle)$ stationary $d h f r-t s^{-}$i.v. $(A)$; $10^{8}$ stationary $d h f r-t s^{-}$s.c. $(B)$; or $10^{8}$ stationary $d h f r-t s^{-}$i.m. $(C)$. One week later, these mice (open symbols) and untreated control mice (solid symbols) were challenged and followed as described for Fig. $3 A$. The results shown are representative of two or three experiments.

tively), while LV39 L. major $\left(5 \times 10^{5}\right.$ cells per $\left.\mathrm{ml}\right)$ induced vigorous proliferation $(116,000 \pm 9000 \mathrm{cpm})$.

\section{DISCUSSION}

Safety. $d h f_{r}-t^{-}$was incapable of establishing a persistent infection or causing disease in the most susceptible strains of mice tested. This defect specifically arises from the lack of $D H F R-T S$, as shown by rescue of $d h f r-t s^{-}$both in vitro and in vivo by thymidine supplementation. As for other intracellular pathogens such as Salmonella, the levels of thymidine available within the parasitophorous vacuole appear insufficient to permit propagation and pathogenesis. Even artificial continuous administration of massive subtoxic thymidine supplementation was only able to partially restore infectivity to $d h f r-t s^{-}$, and lesions immediately regressed upon thymidine withdrawal. Given the tight physiological regulation of thymidine levels (32), it is highly unlikely that rescue could ever occur during natural infections.

Despite the block to propagation and pathogenesis, the low thymidine levels available to Leishmania in vivo are apparently sufficient to prevent or delay classic rapid thymine-less death. This follows because $d h f r-t s^{-}$did not perish immediately in vivo but, instead, slowly declined over a period of months (complete removal of thymidine results in rapid death within a few days in vitro; ref. 24). Thus, subtle interactions between $d h f r-t s^{-}$and the host exist that promote limited persistence simultaneously with differentiation. Minimally, this should prolong the period of exposure to both live and dead parasite antigens, while differentiation of $d h f r-t s^{-}$would deliver substantial quantities of amastigote antigens. These features would seem to be advantagenous to vaccination efforts and may perhaps be unique to $d h f r-t s^{-}$knockouts, relative to other potential candidate attenuating loci that we have considered.

Potential Application of DHFR-TS as a Selective Marker in Vitro and in Vivo. Recently, workers studying prokaryotic pathogens developed powerful strategies for identifying stagespecific genes, based upon the rescue of avirulent auxotrophic pathogens $(36,37)$. In Salmonella and Vibrio, this can be performed by rescue of thy ${ }^{-}$auxotrophs with constructs expressing thymidylate synthase under control of stage-specific promoters (37). Our demonstration that $d h f r-t s^{-}$knockouts are similarly avirulent suggests that expression of DHFR-TS under the control of appropriate Leishmania regulatory elements could be used in an analogous approach.

Vaccination. $d h f r-t s^{-}$was found to be an effective vaccine line for immunizing against cutaneous leishmaniasis, whether delivered by the i.v., s.c., or i.m. routes (Figs. 3 and 4), and in all cases protected against a relatively large challenge dose $\left(10^{6}\right.$ cells) of virulent $L$. major. The fact that $d h f r-t s^{-}$was capable of vaccinating CBA mice by either the s.c. or i.m. routes is highly relevant since these would be preferred in humans. In previous studies, the ability to vaccinate by these routes was generally not observed in the absence of treatment with cytokines. Instead, most workers observed that immunizing with attenuated/avirulent Leishmania by these routes results in an exacerbated course of disease when the mice are subsequently challenged (refs. 7, 8, and 13; for an exception, see ref. 6).

While we have obtained good protection with $d h f r-t s^{-}$, mild infections were always seen after challenge. Protection was not enhanced by vaccinating with metacyclic $d h f r-t s^{-}$or by extending to 1 month the time between vaccination and challenge. Nor did increasing parasite persistence by thymidine supplementation improve protection in BALB/c mice after s.c. vaccination (unpublished results). Ultimately, the effect of stage, route, dosage, and timing will have to be evaluated directly in primates, as the outcome of vaccination strategies could differ considerably from rodents. Another question is whether $d h f r-t s^{-}$L. major can confer cross-protection against other species of Leishmania.

Since it is now possible to introduce and express foreign proteins readily in Leishmania, one could further engineer the $d h f r-t s^{-}$parasite to enlarge or improve its vaccination potential. Candidate proteins that might improve vaccination include immunodominant or protective antigens, lymphokines, or immunomodulatory substances such as those present in the saliva injected by the fly along with Leishmania (38), and expression of several of these has been achieved (39-41). Potentially, dhfr-ts ${ }^{-}$Leishmania could also be used as a platform for introduction of immunoprotective antigens relevant to other diseases.

Prospects for Vaccination of Humans with dhfr-ts ${ }^{-}$Leishmania. $d h f r-t s^{-}$is totally avirulent (Figs. 1 and 2) and elicits protection in mice by routes that have traditionally been used to deliver other vaccines to humans (s.c. and i.m.). These findings and the success of past vaccination campaigns with live Leishmania cause us to be optimistic for the safety and efficacy of dhfr-ts:- vaccination in humans. Since all DHFR-TS sequences have been eliminated, this mutation cannot revert and we have not recovered any second-site thy ${ }^{+}$revertants thus far (unpublished data). Certainly these parasites should be much safer than the ones used in previous vaccinations with live virulent $L$. major, which were given to more than one million people (3).

While our data argue that the $d h f r-t s^{-}$parasite is safe, we have reported (42) that the neomycin phosphotransferase gene used here confers cross-resistance to paromomycin, a drug being used increasingly in antileishmanial chemotherapy. This raises the remote possibility that neomycin phosphotransferase 
genes introduced by vaccination campaigns could escape into virulent populations, depending upon the extent of sexual exchange in Leishmania, which has yet to be convincingly demonstrated. To this end, we have recently succeeded in generating marker-free $d h f r-t s^{-}$deletion $L$. major, which in preliminary tests vaccinate as effectively as the $d h f r-t s^{-}$line tested here (F.J.G.-F. and S.M.B., unpublished results).

Given the unchanging role of DHFR-TS in parasite metabolism, it is likely that $d h f r-t s^{-}$knockouts in other Leishmania species may prove similarly safe and effective. While cutaneous leishmaniasis is rarely life-threatening, mucocutaneous leishmaniasis is more severe and disfiguring and visceral leishmaniasis caused by species of the Leishmania donovani complex is often fatal. The health risk posed by these Leishmania has justifiably precluded tests of live vaccine strains. dhfr-ts ${ }^{-}$ knockouts in viscerotropic species, perhaps in combination with further attenuating mutations, may permit exploration of this vaccination method against visceral leishmaniasis.

Note Added in Proof. Transfection of a functional DHFR-TS gene back into $d h f r-t s^{-}$has recently been shown to restore infectivity to BALB/c mice.

We thank Farrokh Modabber and David Sacks for discussions and encouragement. This work was supported by grants from the Special Programme for Tropical Disease Research of the World Health Organization and National Institutes of Health (R.G.T. and S.M.B.), fellowships from the World Health Organization (F.J.G.-F.) and Brazilian Research Council (L.A.R.d.F.; CNPq 260182/992-3 NV), and the MacArthur Foundation.

1. Titus, R. G., Theodos, C. M., Shankar, A. H. \& Hall, L. R. (1994) in Macrophage-Pathogen Interactions, eds. Zwilling, B. S. \& Eisenstein, T. K. (Dekker, New York), pp. 437-459.

2. Melby, P. C. (1991) Rev. Infect. Dis. 13, 1009-1017.

3. Modabber, F. (1989) Parasitology 98, S49-S56.

4. Howard, J. G. (1986) Int. Rev. Exp. Pathol. 28, 79-116.

5. Greenblatt, C. L. (1988) Parasitol. Today 4, 53-54.

6. Rivier, D., Shah, R., Bovay, P. \& Mauel, J. (1993) Parasite Immunol. 15, 75-84.

7. Liew, F. Y. (1989) in Vaccination Strategies of Tropical Diseases, ed. Liew, F. Y. (CRC, Boca Raton, FL), pp. 239-253.

8. Handman, E., Hocking, R. E., Mitchell, G. F. \& Spithill, T. W. (1983) Mol. Biochem. Parasitol. 7, 111-126.

9. Mitchell, G. F., Handman, E. \& Spithill, T. W. (1984) Aust. J. Exp. Biol. Med. Sci. 62, 145-153.

10. Mitchell, G. F., Handman, E. \& Spithill, T. W. (1985) Int. J. Parasitol. 15, 677-684.

11. Mitchell, G. F. \& Handman, E. (1987) Immunol. Cell Biol. 65, 387-392.

12. Gorczynski, R. M. (1985) Cell. Immunol. 94, 1-10.

13. Marchand, M., Daoud, S., Titus, R. G., Louis, J. \& Boon, T. (1987) Parasite Immunol. 9, 81-92.

14. Kimsey, P. B., Theodos, C.M., Mitchen, T. K., Turco, S. J. \& Titus, R. G. (1993) Infect. Immun. 61, 5205-5213.
15. Shankar, A., Mitchen, T. K., Hall, L. R., Turco, S. J. \& Titus, R. G. (1993) Mol. Biochem. Parasitol. 61, 207-216.

16. Hill, J. O., North, R. J. \& Collins, F. M. (1983) Infect. Immun. 39, 1087-1094.

17. Titus, R. G., Marchand, M., Boon, T. \& Louis, J. A. (1985) Parasite Immunol. 7, 545-555.

18. Muller, I. (1992) Eur. J. Immunol. 22, 3063-3069.

19. de Rossell, R. A., de Jesus de Duran, R., Rossell, O. \& Rodriguez, A. M. (1992) Trans. R. Soc. Trop. Med. Hyg. 86, 251-253.

20. Aebischer, T., Moody, S. F. \& Handman, E. (1993) Infect. Immun. 61, 220-226.

21. Peter, W., Bryceson, A., Evan, D. A., Neal, R. A., Kaye, P., Blackwell, J., Killick-Kendrick, R. \& Liew, F. Y. (1990) Trans R. Soc. Trop. Med. Hyg. 84, 681-689.

22. Yang, D. M., Fairweather, N., Button, L. L., McMaster, W. R., Kahl, L. P. \& Liew, F. Y. (1990) J. Immunol. 145, 2281-2285.

23. Connell, N. D., Medina-Acosta, E., McMaster, W. R., Bloom, B. R. \& Russell, D. G. (1993) Proc. Natl. Acad. Sci. USA 90, 11473-11477.

24. Cruz, A. \& Beverley, S. M. (1990) Nature (London) 348, 171-174.

25. Cruz, A., Coburn, C. M. \& Beverley, S. M. (1991) Proc. Natl. Acad. Sci. USA 88, 7170-7174.

26. Kapler, G. M., Coburn, C. M. \& Beverley, S. M. (1990) Mol. Cell. Biol. 10, 1084-1094.

27. Titus, R. G., Muller, I., Kimsey, P., Cerny, A., Behin, R., Zinkernagel, R. \& Louis, J. (1991) Eur. J. Immunol. 21, 559-567.

28. Sacks, D. L. \& Perkins, P. V. (1984) Science 223, 1417-1419.

29. Titus, R. G., Kelso, A. \& Louis, J. A. (1984) Clin. Exp. Immunol. 55, 157-165.

30. Stocker, B. A. D. (1993) in Biology of Salmonella, eds. Cabello, F., Hormaeche, C., Mastroeni, P. \& Bonina, L. (Plenum, New York), pp. 309-322.

31. Cruz, A. K., Titus, R. \& Beverley, S. M. (1993) Proc. Natl. Acad. Sci. USA 90, 1599-1603.

32. Tattersall, M. H., Brown, B. \& Frei, E., III (1975) Nature (London) 253, 198-200.

33. Bello, A., Nare, B., Freedman, D., Hardy, L. \& Beverley, S. M (1994) Proc. Natl. Acad. Sci. USA 91, 11442-11446.

34. Bretscher, P. A., Wei, G., Menon, J. N. \& Bielefeldt-Ohmann, H (1992) Science 257, 539-542.

35. Scott, P., Pearce, E., Natovitz, P. \& Sher, A. (1987) J. Immunol. 139, 221-227.

36. Mahan, M. J., Slauch, J. M. \& Mekalanos, J. J. (1993) Science 259, 686-688.

37. Mahan, M. J., Slauch, J. M., Hanna, P. C., Camilli, A., Tobias, J. W., Waldor, M. K. \& Mekalanos, J. J. (1994) Infect. Agents Dis. 2, 263-268.

38. Titus, R. G. \& Ribeiro, J. M. C. (1988) Science 239, 1306-1308.

39. Tobin, J. F., Reiner, S. L., Hatam, F., Zheng, S., Leptak, C. L. \& Wirth, D. F. (1993) J. Immunol. 150, 5059-5069.

40. LeBowitz, J. H., Coburn, C. M., McMahon-Pratt, D. \& Beverley, S. M. (1990) Proc. Natl. Acad. Sci. USA 87, 9736-9740.

41. Liu, X. \& Chang, K.-P. (1992) Proc. Natl. Acad. Sci. USA 89, 4991-4995.

42. Gueiros-Filho, F. J. \& Beverley, S. M. (1994) Exp. Parasitol. 78, 425-428. 